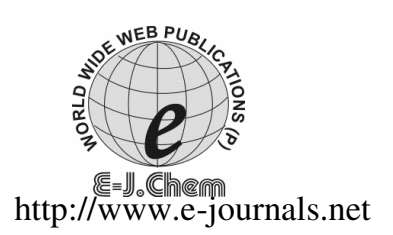

ISSN: 0973-4945; CODEN ECJHAO

E-Journal of Chemistry

2010, 7(4), 1578-1583

\title{
Micellization Studies on Binary Mixture of Methionine with Polyoxyethylene (10) Cetyl Ether (Brij-56) and Polyoxyethylene (20) Cetyl Ether (Brij-58)
}

\author{
B.S.BHADANE and T.J.PATIL
}

\author{
Department of Chemistry, \\ Kisan A.C.S College, Parola, Dist Jalgaon-425111, (M.S.), India. \\ *Department of Chemistry, \\ Z.B.Patil College, Deopur, Dhule. 424002, (M.S.), India. \\ tjpatil123@rediffmail.com
}

Received 11 February 2010; Accepted 5 April 2010

\begin{abstract}
The measurement of cloud point (CP) under the influence of additives provides an excellent tool for investigation of surfactant macromolecule interaction. The CP of pure surfactant polyoxyethylene (10) cetyl ether (Brij-56) and polyoxyethylene (20) cetyl ether (Brij-58) declined with increased [Bj-56] and [Bj-58]. The CP of mixed systems Brij-56/methionine and Brij-58/methionine shows same trends with increased [Met.]. This is mainly due to increased micelle concentrations. The influence of amino acid on the cloud point of Brij-56 and Brij-58 is a clear indication that the phenomenon of clouding is associated with the different micelles coalescing. The phase separation results from micelle-micelle interaction. Considering cloud point as threshold temperature of the solubility, the energetic of clouding process $\left(\Delta \mathrm{G}_{\mathrm{cl}}^{0}, \Delta \mathrm{H}_{\mathrm{cl}}^{0}\right.$ and $\left.\Delta \mathrm{S}_{\mathrm{cl}}^{0}\right)$ have been evaluated using "Phase Separation Model". It is found that the overall clouding process is exothermic and $\Delta \mathrm{H}_{\mathrm{cl}}^{0}>\mathrm{T} \Delta \mathrm{S}_{\mathrm{cl}}^{0}$ indicating that the process of clouding is guided by both enthalpy and entropy. This work supports the conjecture that the cloud point is critical phenomenon rather than the growth of micelles.
\end{abstract}

Keywords: Cloud Point, Brij-56, Brij-58, Methionine, Phase separation model.

\section{Introduction}

Cloud point is one of the important characteristic properties of nonionic surfactant. It is well known that the phase separation occurs in aqueous solution of nonionic surfactant with increase in temperature. The temperature at which this phase separation occurs is known as 'cloud point' (CP). Since this process involved drastic increase in turbidity of solution ${ }^{1}$, a single phase of molecular solution or micellar solution exists below its $\mathrm{CP}$ and above the $\mathrm{CP}$ 
water solubility of surfactant is reduced, this results into cloudy dispersion ${ }^{2}$. The nature of cloud point has been of interest to discuss from two point of view ${ }^{3-5}$. The first one assumes that the nonionic surfactant micelles grow up as one heat the solution to the cloud. Secondly interpreting the observed data in the light of scattering intensity due to the growth of micelles, aggregation number of micelles as a function of the temperature was measured ${ }^{6}$. Cloud point values for mixed system might be a guide to its hydrophilic or hydrophobic character. This information might be useful in pharmaceutical preparations, biomedical formulations or medicinal etc. On contrary, Corti and Degiorgio have interpreted the cloud point as critical point of a binary mixture with a lower consulate point ${ }^{4}$. The critical phenomenon in micellar solution and the micro emulsions is increasingly becoming important and investigated by a number of techniques ${ }^{7-9}$. The interpretation of cloud point as a critical point implies that the critical point is approached the micelle come together and above the critical point, they separate out as the second phase. Various mechanisms have been suggested to explain the phenomenon that includes formation of micelles, solubilization and complex formation ${ }^{10}$. The measurement of CP is of great importance in judging the quality and characteristics of surfactant alone or in a mixture prior to its possible use in a process especially where elevated temperature prevails ${ }^{11}$.

In this paper, the results of our study on the clouding phenomenon of pure Brij-56, Brij-58 and in presence of said amino acid at various concentrations have been reported. These studies are supposed to be landmark in the field of interaction of medicinal preparations, agrochemicals, detergents etc. Considering cloud point as threshold temperature of the solubility, the thermodynamic parameters of clouding process $\left(\Delta \mathrm{G}_{\mathrm{cl}}^{0}, \Delta \mathrm{H}_{\mathrm{cl}}^{0}\right.$ and $\Delta \mathrm{S}_{\mathrm{cl}}^{0}$ have been evaluated using "Phase Separation Model".

\section{Experimental}

The non-ionic surfactant Brij-56 was the product of Aldrich (m.wt.682) and Brij-58 was the product of sigma, USA (m.wt.1122). These surfactants were used as received. The amino acid methionine (m.wt.149.21) was the products of Thomas Baker (99\% Purity). Doubly distilled water with Sp.conductance $2-4 \mu \mathrm{S} \mathrm{cm}^{-1}$ at $303.15 \mathrm{~K}$ was used in the preparation of all solutions of different concentrations. The cloud point (CP) was determined by controlled heating of the sample solutions in thin glass tube immersed in beaker containing water, the sample solution was stirred while being heated. The heating rate of sample was controlled by less than $1{ }^{\circ} \mathrm{C} / \mathrm{min}$. The detailed procedure was given in our previous publications ${ }^{12}$. The reproducibility of the measurement found to be within $\pm 0.2{ }^{\circ} \mathrm{C}$. As the $\mathrm{CP}$ values are not small, the observed values have been rounded off to the nearest degree and presented in the tables.

\section{Clouding species}

Additives amino acid

$$
\begin{array}{cc}
\mathrm{C}_{16} \mathrm{H}_{33}\left(-\mathrm{OCH}_{2}-\mathrm{CH}_{2}\right)_{\mathrm{n}} \mathrm{OH} & \mathrm{n}=10 \\
\mathrm{Brij}^{-56(\mathrm{Bj}-56)} & \\
\mathrm{C}_{16} \mathrm{H}_{33}\left(-\mathrm{OCH} \mathrm{CH}_{2}-\mathrm{CH}_{2}\right)_{\mathrm{n}} \mathrm{OH} & \mathrm{n}=20 \\
\text { Brij-58(Bj-58) } &
\end{array}
$$<smiles>CSCCC(N)C(=O)O</smiles>

Methionine (Met.)

Figure 1. Molecular structures of clouding species and additives 


\section{Results and Discussion}

\section{Cloud points of pure Brij-56 and Brij-58}

The cloud points of pure surfactant, Brij-56 at various concentrations in wt $\%$ are given in Table 1 . The CP of the surfactant was found to be decreased with increased [Bj-56]. This is due to increase in micelle concentration. The phase separation occurs due to micelle-micelle interaction. It is also observed that below $0.5 \mathrm{wt} \%$ there is mild decreased in cloud point. This is mainly due to lower concentration of surfactant moiety required to form agglomerate of visible micelle.

Table 1. Cloud points of pure Brij-56

\begin{tabular}{cccc}
\hline $\mathrm{Wt} \%$ Brij-56 & Molarity $\times 10^{-3}$ & Mole fraction $\times 10^{-4}$ & $\mathrm{Cp} /{ }^{0} \mathrm{C}$ \\
\hline 0.5 & 7.331 & 1.3184 & 66.0 \\
1.0 & 14.663 & 2.6365 & 63.2 \\
2.0 & 29.326 & 5.2716 & 62.0 \\
3.0 & 43.988 & 7.9053 & 61.0 \\
4.0 & 58.651 & 10.538 & 60.2 \\
5.0 & 73.314 & 13.167 & 58.6 \\
\hline
\end{tabular}

Similar results as said above was observed for pure surfactant Brij-58 at various concentrations in wt $\%$, which are given in Table 2. It should be noted that the phase separation in Brij-58 occurs slightly at temperature than in Brij-56. This might be indicated the micelle-micelle interaction is greater in Brij-58 that in Brij-56.

Table 2. Cloud points of pure Brij-58

\begin{tabular}{cccc}
\hline Wt \% Brij-58 & Molarity $\times 10^{-3}$ & Mole fraction $\times 10^{-4}$ & $\mathrm{Cp} /{ }^{0} \mathrm{C}$ \\
\hline 0.5 & 4.456 & 0.8014 & 96.3 \\
1.0 & 8.913 & 1.6028 & 95.0 \\
2.0 & 17.825 & 3.2060 & 94.2 \\
3.0 & 26.738 & 4.8090 & 93.5 \\
4.0 & 35.651 & 6.4120 & 92.1 \\
5.0 & 44.563 & 8.0150 & 91.7 \\
\hline
\end{tabular}

\section{Brij-56 / methionine and Brij-58/methionine systems}

The influence of methionine (Met.) on the CP of Brij-56 and Brij-58 at different [methionine] has been given in Table $3 \& 4$. These results indicating that the cloud point of surfactant declined considerably with increased [methionine]. This is due to the removal of water from surfactant by added amino acid and helps the surfactant micelles to come closer with each other resulting into lowering of CP. In both systems below $0.5 \mathrm{wt} \%$ concentration, there is no remarkable change in $\mathrm{CP}$ but at higher concentration the surfactant molecules get saturated with added amino acid moieties and makes more hydrophobic to manifest rapid lowering of $\mathrm{CP}^{13}$. The dependence of CP of Brij-56 and Brij-58 on [methionine] is depicted in Figure 2a and $2 \mathrm{~b}$.

Table 3. Influence of methionine on CP of Brij-56

\begin{tabular}{ccccccc}
\hline \multirow{2}{*}{ Wt\% Brij-56 } & \multicolumn{7}{c}{ Wt \% of methionine } \\
\cline { 2 - 7 } & 0.5 & 1.0 & 2.0 & 3.0 & 4.0 & 5.0 \\
\hline 0.5 & 63.0 & 61.5 & 60.2 & 59.4 & 57.8 & 56.3 \\
1.0 & 62.5 & 60.7 & 58.5 & 58.0 & 56.4 & 53.5 \\
2.0 & 61.2 & 59.0 & 57.2 & 56.5 & 56.0 & 52.6 \\
3.0 & 60.7 & 58.2 & 56.0 & 55.2 & 54.0 & 51.0 \\
4.0 & 60.0 & 57.4 & 55.0 & 54.7 & 53.3 & 50.7 \\
5.0 & 57.0 & 56.5 & 53.7 & 53.0 & 50.2 & 48.0 \\
\hline
\end{tabular}




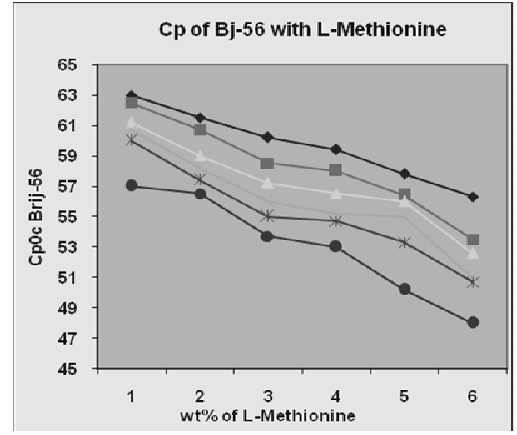

Figure 2 (a). CP of Brij56

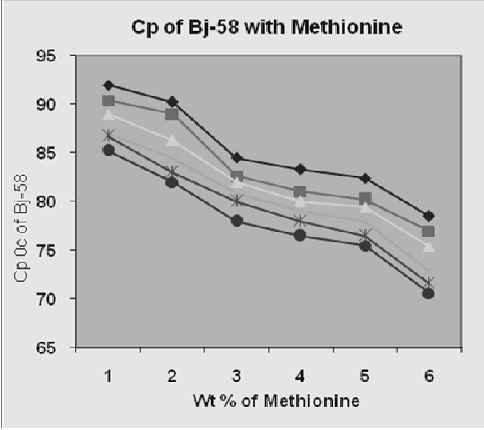

Figure 2 (b). CP of Brij-58

\section{Thermodynamics of clouding}

All physicochemical processes are energetically controlled. The spontaneous formation of micelle is obviously guided by thermodynamic principles. The energetic of such processes are required for formulation, uses and basic understanding. Thermodynamic parameters of pure Brij-56, Brij-58 and mixed system Brij-56/methion, Brij-58/methionine are given in Table 4-8. In case of non-ionic surfactant, the desolvation of hydrophilic groups of the surfactant leads to the formation of cloud or turbidity in the surfactant solution at elevated temperature. The appearance of cloud point is entropy dominated. At the cloud point, the water molecules get very detached from the micelles.

Table 4. Influence of methionine on $\mathrm{CP}$ of Brij-58

\begin{tabular}{ccccccc}
\hline \multirow{2}{*}{ Wt\% Brij-58 } & \multicolumn{7}{c}{ Wt \% of methionine } \\
\cline { 2 - 7 } & 0.5 & 1.0 & 2.0 & 3.0 & 4.0 & 5.0 \\
\hline 0.5 & 92.0 & 90.2 & 84.5 & 83.3 & 82.4 & 78.5 \\
1.0 & 90.4 & 89.0 & 82.6 & 81.0 & 80.2 & 75.4 \\
2.0 & 89.0 & 86.3 & 82.0 & 80.0 & 79.4 & 74.5 \\
3.0 & 87.0 & 84.4 & 80.8 & 79.0 & 78.0 & 72.8 \\
4.0 & 86.7 & 83.0 & 80.0 & 78.0 & 76.5 & 71.6 \\
5.0 & 85.2 & 82.0 & 78.5 & 76.5 & 75.5 & 70.6 \\
\hline
\end{tabular}

Table 5. Thermodynamic parameter $\mathrm{CP}$ of Brij-56

\begin{tabular}{cccc}
\hline $\mathrm{Wt} \%$ Brij-56 & $\Delta \mathrm{G}_{\mathrm{cl}} \mathrm{kJmole}^{-1}$ & $-\Delta \mathrm{H}_{\mathrm{cl}} \mathrm{kJmole}^{-1}$ & $-\Delta \mathrm{S}_{\mathrm{cl}} \mathrm{Jmole}^{-1}$ \\
\hline 0.5 & 25.1 & & 493.07 \\
1.0 & 23.0 & 141.97 & 490.78 \\
2.0 & 21.0 & & 486.54 \\
3.0 & 19.8 & & 484.43 \\
4.0 & 18.9 & 483.07 \\
5.0 & 18.3 & & 483.26 \\
\hline
\end{tabular}

Table 6. Thermodynamic parameter CP of Brij-58

\begin{tabular}{cccc}
\hline $\mathrm{Wt} \%$ Brij-58 & $\Delta \mathrm{G}_{\mathrm{cl}} \mathrm{kJmole}^{-1}$ & $-\Delta \mathrm{H}_{\mathrm{cl}} \mathrm{kJmole}^{-1}$ & $-\Delta \mathrm{S}_{\mathrm{cl}} \mathrm{Jmole}^{-1}$ \\
\hline 0.5 & 29.0 & & 654.56 \\
1.0 & 26.7 & 212.78 & 650.84 \\
2.0 & 24.6 & & 646.57 \\
3.0 & 23.3 & 644.09 \\
4.0 & 22.3 & 643.90 \\
5.0 & 21.6 & & 642.70 \\
\hline
\end{tabular}


Table 7. Thermodynamic parameter of Brij-56/methionine

\begin{tabular}{cccc}
\hline $\mathrm{Wt} \%$ Brij-56 & $\Delta \mathrm{G}_{\mathrm{cl}} \mathrm{kJmole}^{-1}$ & $-\Delta \mathrm{H}_{\mathrm{cl}} \mathrm{kJmole}^{-1}$ & $-\Delta \mathrm{S}_{\mathrm{cl}} \mathrm{J}$ mole $^{-1}$ \\
\hline 0.5 & 20.7 & 224.19 & 728.87 \\
1.0 & 18.7 & 192.45 & 629.49 \\
2.0 & 16.7 & 128.05 & 433.26 \\
3.0 & 15.6 & 126.92 & 427.08 \\
4.0 & 14.8 & 118.00 & 398.71 \\
5.0 & 14.0 & 114.66 & 389.95 \\
\hline
\end{tabular}

Table 8. Thermodynamic parameter of Brij-58/methionine

\begin{tabular}{cccc}
\hline $\mathrm{Wt} \%$ Brij-58 & $\Delta \mathrm{G}_{\mathrm{cl}} \mathrm{kJmole}^{-1}$ & $-\Delta \mathrm{H}_{\mathrm{cl}} \mathrm{kJmole}^{-1}$ & $-\Delta \mathrm{S}_{\mathrm{cl}} \mathrm{Jmole}^{-1}$ \\
\hline 0.5 & 22.5 & 176.14 & 544.22 \\
1.0 & 20.3 & 144.54 & 453.62 \\
2.0 & 18.1 & 143.55 & 446.66 \\
3.0 & 16.8 & 140.19 & 436.16 \\
4.0 & 15.9 & 135.50 & 421.05 \\
5.0 & 15.2 & 134.30 & 417.43 \\
\hline
\end{tabular}

Considering cloud point as the phase separation point, the thermodynamic parameters such as standard free energy $\left(\Delta \mathrm{G}_{\mathrm{cl}}\right)$, enthalpy $\left(\Delta \mathrm{H}_{\mathrm{cl}}\right)$ and entropy $\left(\Delta \mathrm{S}_{\mathrm{cl}}\right)$ for the clouding process have been calculated using the Phase separation Model ${ }^{14}$.

$$
\Delta \mathrm{G}_{\mathrm{cl}}=-\mathrm{RT} \ln \mathrm{Xs}
$$

Where "cl" stands for clouding process and $\ln \mathrm{Xs}$ is the mole fractional solubility of the solute. The standard enthalpy $\left(\Delta \mathrm{H}_{\mathrm{cl}}\right)$ for the clouding process have been calculated from the slope of the linear plot of of $\ln \mathrm{Xs} v s .1 / \mathrm{T}_{0}$ in Figure 3(a) and Figure 3(b).

$$
\mathrm{d} \ln \mathrm{Xs} / \mathrm{dT}=\Delta \mathrm{H}_{\mathrm{cl}} / \mathrm{RT}
$$

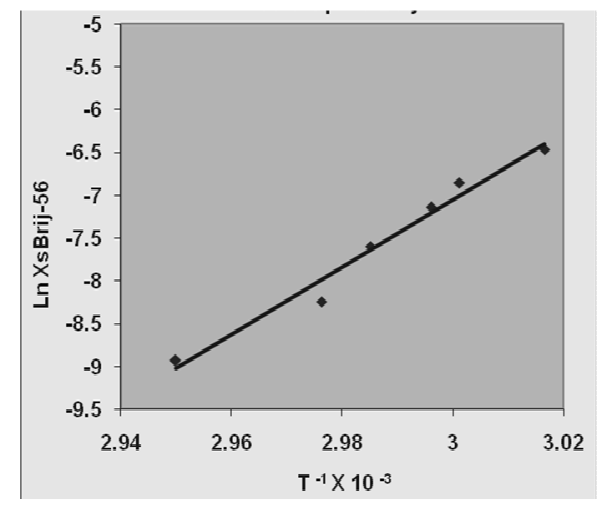

Figure 3(a). CP of Brij 56 at different conc.

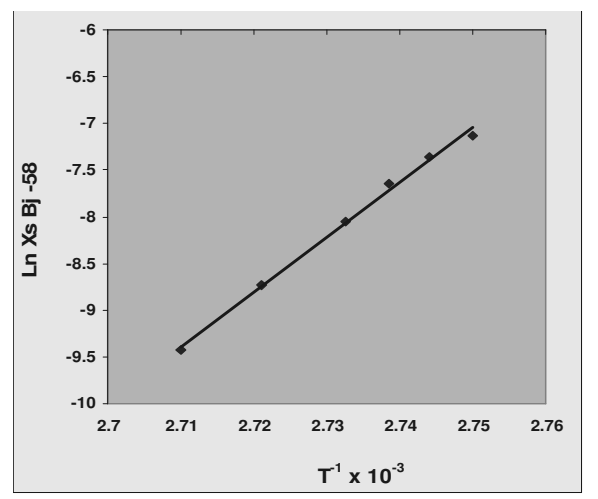

Figure 3 (b). CP of Brij 58 at different conc.

The standard free energy $\left(\Delta \mathrm{S}_{\mathrm{cl}}\right)$ of the clouding process have been calculated from the following relationship

$$
\Delta \mathrm{S}_{\mathrm{cl}}^{0}=\left(\Delta \mathrm{H}_{\mathrm{cl}}^{0}-\Delta \mathrm{G}_{\mathrm{cl}}\right) /
$$


The thermodynamic parameters for pure surfactant and in mixed systems are given in Table 3 and Table $4 . \Delta \mathrm{H}_{\mathrm{cl}}^{0}<\Delta \mathrm{G}_{\mathrm{cl}}^{0}$ indicating that overall clouding process is exothermic and also $\Delta \mathrm{H}^{0}{ }_{\mathrm{cl}}>\mathrm{T} \Delta \mathrm{S}_{\mathrm{cl}}^{0}$ indicate that the process of clouding is guided by both enthalpy and entropy ${ }^{15}$.

The present work would be supportive evidence regarding the probable interaction between non-ionic surfactant and macromolecules leading to the phase separation at the cloud point. The effect of amino acids on the cloud point is a clear indication that the phenomenon of clouding is associated with the different micelles coalescing. This paper supports the conjecture that the cloud point is a critical phenomenon.

\section{Conclusion}

- The CP of pure surfactant polyoxyethylene (10) cetyl ether and polyoxyethylene (20) cetyl ether declines with increased in its concentration due to increased micelle concentration.

- The CP of mixed system Brij-56/methionine and Brij-58/methionine shows same trend with the different micelle coalescing.

- At elevated temperature phase separation results from micelle-micelle interactions.

- Energetic of clouding process found to be exothermic and $\Delta \mathrm{H}_{\mathrm{cl}}^{0}>\mathrm{T} \Delta \mathrm{S}_{\mathrm{cl}}^{0}$ indicating that the process of clouding is guided by both enthalpy and entropy.

\section{Acknowledgment}

The author (B.S.Bhadane) thankful to University Grand Commission, WRO, Pune for financial support to perusing this research work, Hon'ble Principal, Z.B.Patil College, Dhule, Hon'ble Principal, Kisan A.C.S.College, Parola Dist., Jalgaon, Head, Department of Chemistry, Z.B.Patil College, Dhule and Head, Department of Chemistry, Kisan A.S.C.College, Parola Dist.,Jalgaon.for providing laboratory facilities.

\section{References}

1. Lindman B and Thaiberg K, Polymer-Surfactant Interactions Recent Developments, in Interactions of Surfactant with the Polymers and Proteins (C R C Press Boca Raton, FL, 1993), Chapter 5.

2. Nagarajan R, Colloids Surf., 1985, 1,13.

3. Schubert K V, Strey R and Kahlweit M, J Colloid Interface Sci., 1991, 141, 21-29.

4. Mdyneux P, Water-Soluble Synthetic Polymers Properties and behaviour CRC Press Boca raton, FL; Vol.II Chapter, 1984, 2.

5. Shinoda K, Nakagawa T, Tamamushi B and Ishemushi T, Colloidal Surfactants Academic Press, New York/London, 1967, 12.

6. Arai H, Murata M and Shinoda K, J Colloidal Interface Sci., 1971, 37, 223-227.

7. Kjellander R, J Chem Soc Faraday Trans 2, 1982, 78, 2025.

8. Blakschlein D, Thurston G M and Benedeck G B, J Chem Phy., 1986, 85, 7268-7288.

9. Rupert L A M, J Colloid Interface Sci., 1992, 92, 153.

10. Schott H and Royce A E, J Pharm Sci., 1984, 73, 793.

11. Ghosh S and Moulik S P, Indian J Chem., 1999, 38, 207.

12. Bhadane B S and Patil T J, Oriental J Chem., 2008, 24(3), 253-256.

13. Marszall L, Langmuir, 1988, 4, 90.

14. Attwood D and Florence A T, Surfactant Systems Champman and Hall London, 1983, 99.

15. Patil T J and Patil H A, Int J Chem Sci., 2005, 3(3), 507. 


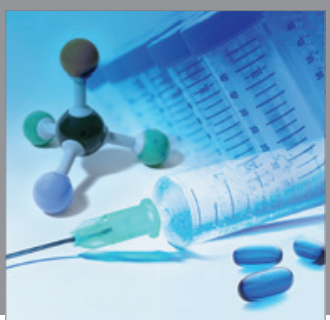

International Journal of

Medicinal Chemistry

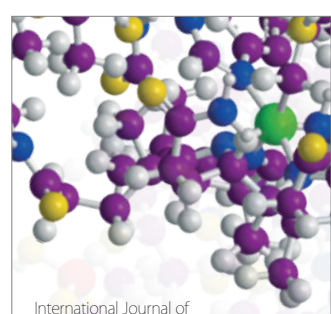

Carbohydrate Chemistry

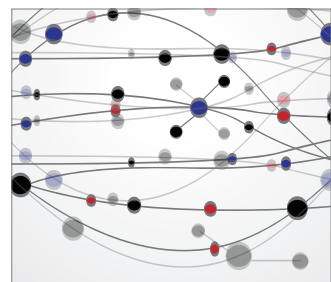

The Scientific World Journal
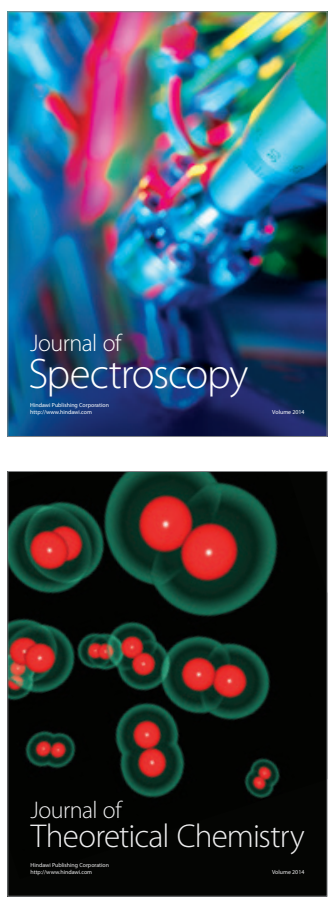
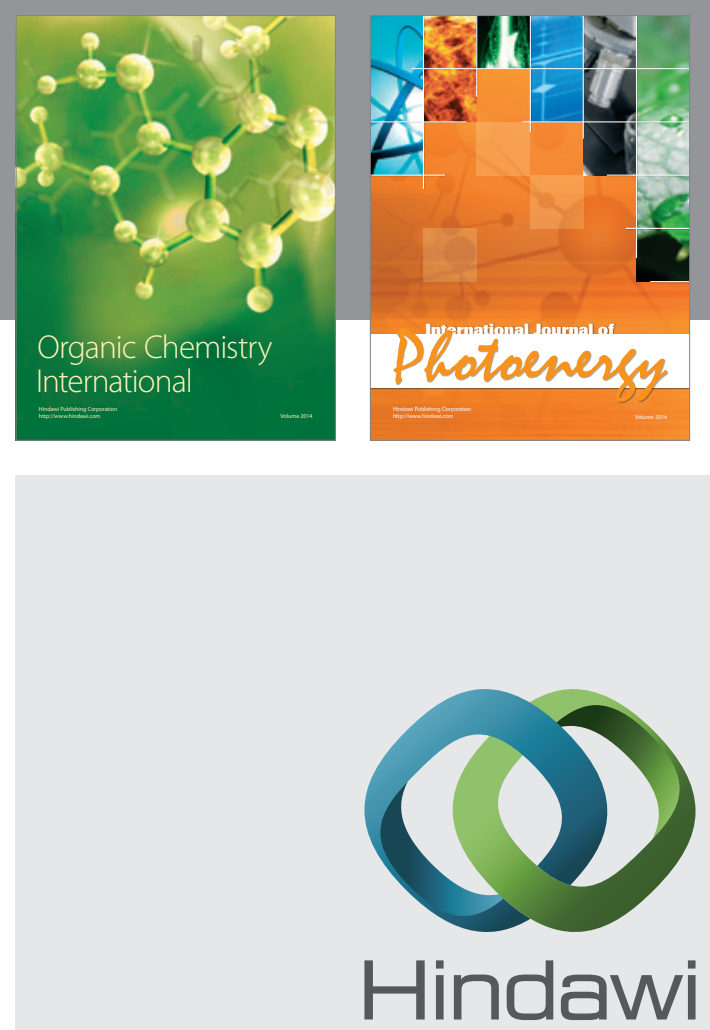

Submit your manuscripts at

http://www.hindawi.com
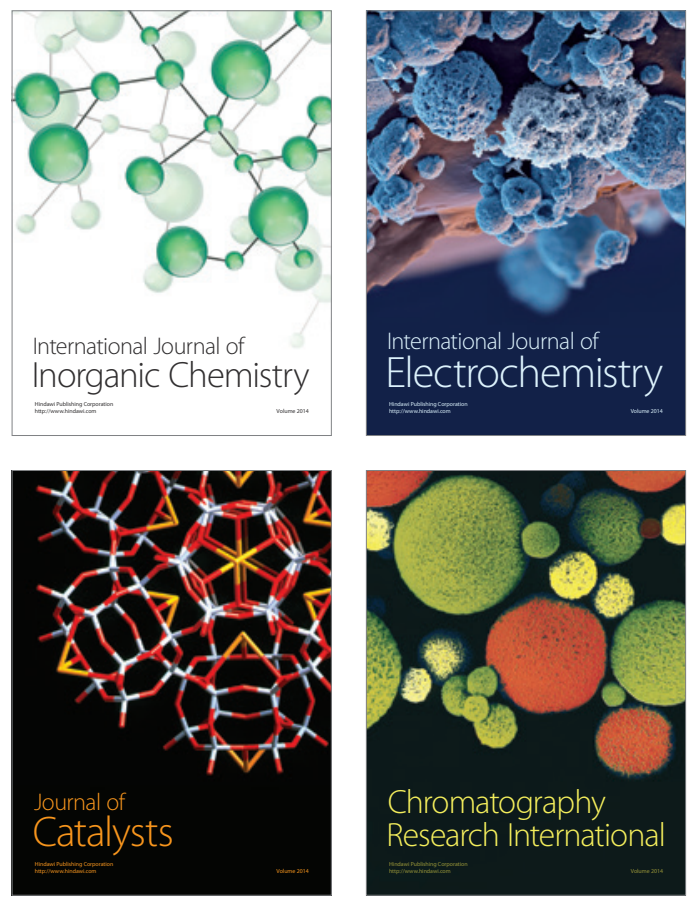
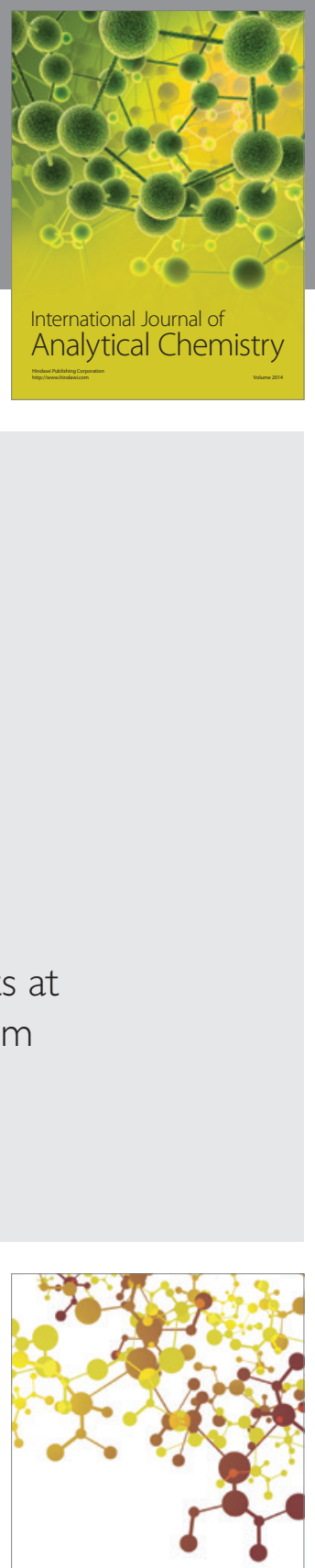

Journal of

Applied Chemistry
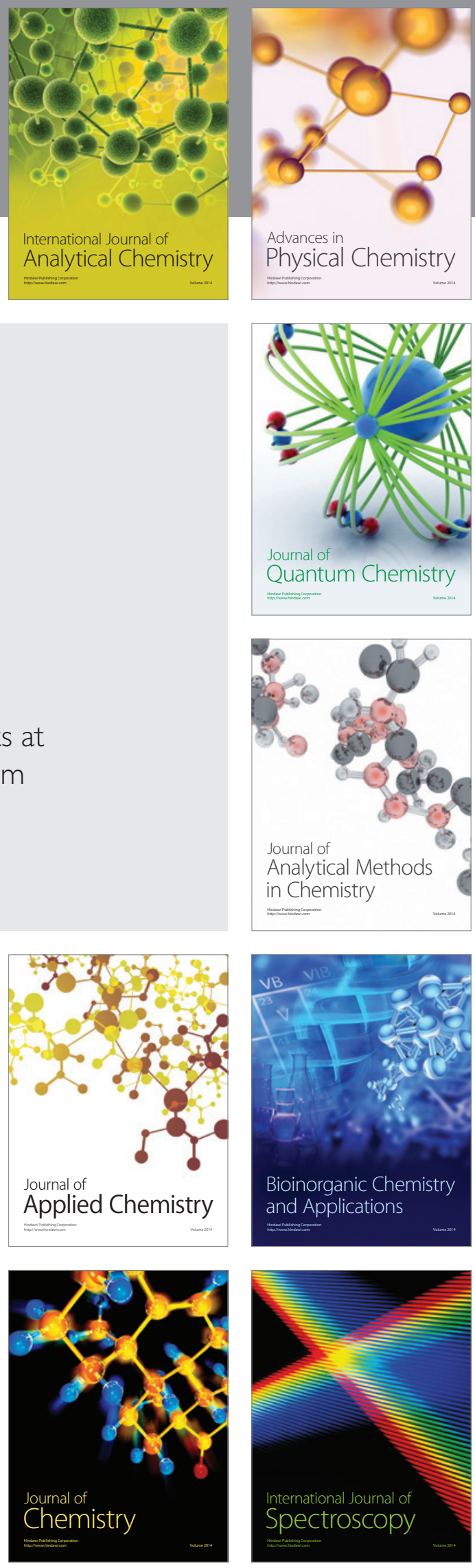